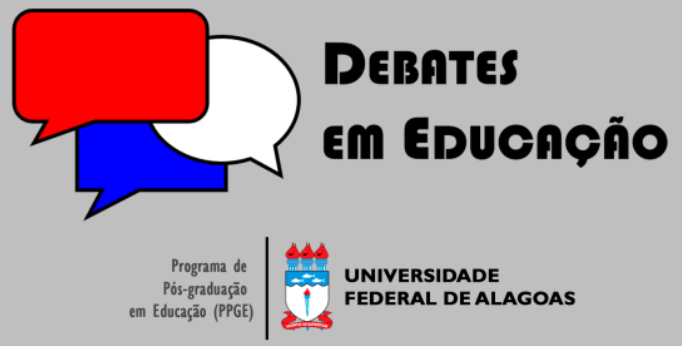

ISSN Eletrônico 2175-6600

Vol. 12 | Nº 26 | Jan./Abr. | 2020

Josiane de Cássia Zaneti

9 iD

Universidade Estadual Paulista (UNESP)

josianezaneti@gmail.com

Hederson Aparecido de Almeida

(9) iD

Universidade Estadual Paulista (UNESP)

hederson.almeida@unesp.br

Matheus Zaffani Borges

9 iD

Universidade Estadual Paulista (UNESP) matheuszaffani@hotmail.com

Renato Eugênio da Silva Diniz (9) iD

Universidade Estadual Paulista (UNESP) renato.es.diniz@unesp.br

\section{CONHECIMENTOS CLÁSSICOS, TRABALHO EDUCATIVO E ENSINO DE CIÊNCIAS: ARTICULAÇÕES POSSÍVEIS A PARTIR DA PEDAGOGIA HISTÓRICO-CRÍTICA}

\begin{abstract}
RESUMO
A pedagogia histórico-crítica ( $\mathrm{PHC}$ ) é a teoria da educação embasada no materialismo histórico dialético. Sob essa perspectiva, a especificidade da educação no contexto escolar consiste na transmissão e apropriação dos conhecimentos historicamente elaborados. Visto isso, este ensaio teórico objetivou discutir sobre possíveis interações entre os princípios 'conhecimentos clássicos' e 'trabalho educativo' respaldados na $\mathrm{PHC}$, articulando-os ao ensino de Ciências e Biologia. A partir do diálogo com os referenciais teóricos enfatizamos que a socialização dos conhecimentos clássicos na forma de conteúdos escolares, por meio do trabalho educativo, é condição precípua para que o ensino de Ciências se concretize sob a perspectiva histórico dialética.
\end{abstract}

Palavras-chave: Educação. Ensino de Ciências Naturais e Biologia. Formação de professores. Materialismo histórico dialético.

\section{CLASSIC KNOWLEDGE, EDUCATIONAL WORK AND SCIENCE TEACHING: POSSIBLE LINKS WITH THE HISTORICAL-CRITICAL PEDAGOGY \\ ABSTRACT}

Historical-Critical Pedagogy (PHC) is the education theory based on historical dialectical materialism. From this perspective, the specificity of scholar education consists in the transmission and appropriation of the historically elaborated knowledge. Therefore, this theoretical essay aimed to discuss possible interactions between the principles of 'classical knowledge' and 'teaching work', supported by $\mathrm{PHC}$, linking them to the teaching of Science and Biology. From the dialogue with the theoretical frameworks, we emphasize that the socialization of the classic knowledge, in the form of school contents, through educational work, is the main condition so that the Science teaching to be realized from the historical dialectical perspective.

Keywords: Education. Natural Sciences and Biology teaching. Historical dialectical materialism. Teacher education.

Submetido em: 13/03/2019

Aceito em: $01 / 11 / 2019$

Publicado em: 06/04/2020

do http://dx.doi.org/10.28998/2 I 75-6600.2020v I 2n26p302-322 


\section{INTRODUÇÃO}

O presente ensaio teórico objetivou discutir sobre possíveis interações entre os princípios 'trabalho educativo' e 'conhecimento clássico' no ensino de Ciências à luz da pedagogia histórico-crítica (PHC). A escolha dos referidos conceitos não é aleatória, uma vez que estão diretamente relacionados com o trabalho pedagógico da escola do professor e com a aprendizagem de estudantes em sala de aula.

A PHC se fundamenta no materialismo histórico dialético com o intuito de, segundo Saviani (20 I I, p. 76), "compreender a questão educacional com base no desenvolvimento histórico objetivo". Esse movimento histórico, empreendido pela teoria, significa a compreensão da educação como originada do processo de produção da própria existência material humana, a partir de sua ação transformadora sobre a natureza por meio do trabalho (SAVIANI, 20 I I). Tal compreensão se completa assumindo que a educação é condicionada pela estrutura social, por isso é uma pedagogia crítica e é também dialética, pois sabe que tem um papel a desempenhar e que, embora determinada pela sociedade, também pode influenciá-la. Nas palavras Saviani (2012, p. 65-66),

[...] longe de entender a educação como determinante principal das transformações sociais, reconhece ser ela um elemento secundário e determinado. [...] entende que a educação se relaciona dialeticamente com a sociedade. Nesse sentido, ainda que elemento determinado, não deixa de influenciar o elemento determinante. Ainda que secundário, nem por isso deixa de ser instrumento importante e por vezes decisivo no processo de transformação da sociedade.

O conceito de 'trabalho educativo', segundo Silva (2017), é fundamental para a compreensão da PHC. O autor faz uma análise dos fundamentos ontológicos desse conceito por meio do estudo do trabalho como mediação entre o ser humano e a natureza. Silva (2017) afirma que o conceito foi desenvolvido no início dos anos 1980 pelo professor Dermeval Saviani. $\bigcirc$ trabalho educativo relaciona-se com a educação escolar, e esta atividade é trabalho, ainda que o produto resultante não seja de natureza material, pois se volta para a questão do saber. Sendo assim, desenvolveremos a definição de trabalho educativo com base nas pesquisas realizadas pelo professor Saviani (20 I I).

O conceito de 'conhecimentos clássicos' está relacionado à questão do saber. Nessa perspectiva educacional crítica, isso aponta para a função da escola, que é a socialização do saber sistematizado. Diversos trabalhos (GIARDINETTO, 20 I0; LAVOURA; MARSIGLIA, 20 I 5; LAVOURA; MEIRELES, 20 I3) indicam o conceito como elemento essencial no processo de socialização dos conteúdos na escola.

Como será discutido mais à frente, os conhecimentos clássicos estão associados às máximas conquistas de desenvolvimento da humanidade em diversas áreas, como as Ciências, dentre outras.

\footnotetext{
I Não é objetivo deste artigo explicitar sobre esta teoria. Por esta razão, para saber mais sobre fundamentos e o desenvolvimento coletivo da PHC, recomendamos as obras "Escola e Democracia" e "Pedagogia histórico-crítica: primeiras aproximações" de Dermeval Saviani, assim como "Pedagogia histórico-crítica: 30 anos" organizada por Ana Carolina Galvão Marsiglia, todas da editora Autores Associados.
} 
Contudo, a sua transmissão no contexto escolar não está desvinculada da luta de classes na sociedade capitalista que vivemos. Na escola, a luta de classes se manifesta quando a socialização (ou não) dos conhecimentos clássicos está em disputa (SAVIANI, 20I I).

Partimos do ponto de vista da necessidade dessa socialização. Dessa forma, a 'prática social' para a PHC é o ponto de partida e o ponto de chegada do trabalho educativo. Porém, a compreensão e a vivência da prática social são enriquecidas no ponto de chegada. Nesse sentido, o trabalho educativo deve agir sempre em movimento contínuo e crescente, utilizando os conhecimentos clássicos, traduzidos em saberes escolares, na promoção de um estado de desenvolvimento estudantil do empírico sincrético, por meio da abstração, ao concreto sintético (BATISTA; LIMA, 20I2; SAVIANI, 20I, 20I 2).

No âmbito específico do Ensino de Ciências (EC), segundo Santos (2005), há a hegemonia de três tendências: o ensino com base na História da Ciência, o ensino a partir da aproximação ao cotidiano e aquele pautado pelo uso da experimentação. $\bigcirc$ autor, a partir da análise dessas tendências, faz algumas críticas sobre a forma como elas vêm sendo difundidas. Para Santos (2005), elas desconsideram, muitas vezes, os aspectos sociais, econômicos e políticos que influenciam a própria Ciência e o seu ensino.

Vale ressaltar ainda que tais tendências se enquadram dentro do ideário do construtivismo, que é a maior influência para o EC contemporâneo, de acordo com Matthews (2000). Apesar da importância que atribui às tentativas de valorização do conhecimento prévio do aluno, aos conceitos científicos e na tentativa de promoção do envolvimento dos estudantes em sala, o construtivismo possui como principal falha as explicações ingênuas e empiristas sobre o conhecimento. $\bigcirc$ autor é enfático ao dizer que o slogan 'construtivismo' virou um jargão, muito mais do que uma teoria bem fundamentada. Além disso, para os professores que ensinam Ciências, o construtivismo muito pouco contribui como referencial orientador.

Neste sentido, defendemos uma pedagogia que seja histórica e crítica para o EC, visto que os pressupostos construtivistas não têm proporcionado aos alunos a aprendizagem que proclamavam promover. Além disso, diferente da PHC, secundarizam a transmissão dos conhecimentos clássicos em função do desenvolvimento de habilidades e competências, sem os quais é negada aos alunos a apropriação das formas mais desenvolvidas da cultura humana.

Posto isso, na primeira seção introduziremos o conceito de 'trabalho educativo' e o relacionaremos com a categoria 'trabalho'. Em seguida, discutiremos a definição de 'conhecimentos clássicos' na intenção de evidenciar a importância da sua transmissão no contexto escolar. Por fim, na última seção, refletiremos sobre a relação do trabalho educativo, dos conhecimentos clássicos, fazendo a defesa do EC pautado em uma pedagogia histórica e dialética de Educação.

\section{TRABALHO EDUCATIVO ENQUANTO ESPECIFICIDADE HUMANA}


Não há história social se não houver transformação da realidade humana, se não houver desenvolvimento. Mas não há desenvolvimento humano se não houver a transformação das necessidades humanas, seja pela modificação das formas de satisfação de necessidades anteriormente existentes, seja pelo surgimento de novos tipos de necessidades (DUARTE, 20I3, p. 33).

Nossa existência, enquanto seres humanos que somos hoje, é guiada pela transformação constante das nossas necessidades. Este princípio é levado ao extremo pelo sistema, para a manutenção do modo de produção capitalista.

A transformação da nossa realidade se dá por meio do trabalho (alienado ou não) que transforma a natureza e a coloca a serviço de nossas necessidades. Estas, no mundo social que criamos, exigem mais que alimentação e reprodução - vão muito além da fundamental necessidade de sobrevivência. Na canção "Comida" lançada no ano de 1987, o grupo Titãs expressou objetivamente nossa complexa condição humana: "A gente não quer só comida / A gente quer comida, diversão e arte / A gente não quer só comida / A gente quer saída para qualquer parte"2.

Nossa natureza biológica, identificada pela categoria biológica da espécie humana (Homo sapiens, subespécie Homo sapiens sapiens), que nos coloca no reino animal como mamíferos primatas hominídeos, nos é inata e pode ser mantida apenas por meio da sobrevivência. Essa natureza biológica garante a sobrevivência física do ser humano, que é assegurada pelo nascimento e pela reprodução biológica dos indivíduos, permitindo a continuidade de nossa espécie (DUARTE, 20।3).

No entanto, ao longo do processo da evolução de nossa espécie, desenvolvemos uma 'segunda natureza humana'. A transformação das nossas necessidades por meio do trabalho, e a submissão da natureza para satisfazê-las fez com que desenvolvêssemos características que não nos são inatas, mas que foram construídas ao longo da história humana. Isto é o que nos diferencia dos demais animais e que deve ser transmitido de uma geração a outra. Desenvolvemos a cultura. Isso significa que o hominídeo - ser biológico - precisa produzir sua condição humanizada para garantir sua existência como ser histórico (LESSA; TONET, 20I I). E é por isso que esses autores afirmam que o trabalho se configura como a categoria fundante do ser humano.

A PHC entende que o trabalho, enquanto 'atividade vital humana', possui duas funções: assegurar a existência individual ao mesmo tempo em que assegura a existência da sociedade. Neste sentido, ao construir materialmente a sociedade, os humanos lançam as bases para a sua própria construção enquanto indivíduos. (LESSA; TONET, 20I I).

Para tal, é necessário ter conhecimento e a sua transmissão entre as gerações de forma que exista uma possível continuidade no desenvolvimento social. Duarte (20।3) afirma que toda nova geração de

2 Estrofe da letra de "Comida" composta por Marcelo Fromer, Arnaldo Antunes e Sérgio Britto. "Comida" integra o álbum "Jesus não tem dentes no país dos banguelas", gravado em 1987 sob selo WEA. 
indivíduos que nasce herda dos antecedentes um legado histórico que condiciona a sua ação. Tal condição é um meio para o desenvolvimento de sua criatividade, para a sua transformação.

Lavoura e Meireles (2013, p. 98) argumentam que é necessário ao ser humano:

[...] um processo educativo para que ele possa satisfazer suas necessidades de existência. Portanto, a educação tem origem neste processo de trabalho. Os homens não nascem sabendo realizar trabalho, eles necessitam ser ensinados a trabalhar. Trabalho e educação são, portanto, fundamentos ontológicos.

A educação, portanto, faz parte do processo de formação humana. É por essa razão que a PHC se dedica ao desenvolvimento de uma teoria pedagógica que possa contribuir para o desenvolvimento do potencial contido em cada estudante. Por isso, a importância do princípio 'trabalho educativo' dentro do processo de transmissão e apropriação dos 'conhecimentos clássicos'.

Como o objeto da PHC é a educação escolar, a ela interessa a parte do processo de humanização das novas gerações que ocorre através da mediação do trabalho educativo nas escolas. Saviani (20l I, p. 13, destaque nosso) afirma que:

[...] o que não é garantido pela natureza tem que ser produzido historicamente pelos homens, e aí se incluem os próprios homens. Podemos, pois, dizer que a natureza humana não é dada ao homem, mas é por ele produzida sobre a base da natureza biofísica. Consequentemente, o trabalho educativo é o ato de produzir, direta e intencionalmente, em cada indivíduo singular, a humanidade que é produzida histórica e coletivamente pelo conjunto dos homens.

Assim, o trabalho educativo deve ser entendido como uma característica exclusiva do ser humano histórico, derivada de sua atividade vital - o trabalho - que contribui para a continuidade da humanidade por meio da transmissão da cultura enquanto condição para sua constante superação e consequente desenvolvimento.

Por se tratar de uma ação direta e intencional de produzir a humanidade nos indivíduos, o trabalho educativo na perspectiva da PHC se diferencia de outras formas de educação, consideradas espontâneas (DUARTE, 2008). Apesar das diferentes formas de educação também terem uma finalidade, serem intencionais, somente o trabalho educativo na perspectiva da PHC é que tem a intenção de produzir a humanidade nos indivíduos, diferenciando-se das demais por esse e outros elementos.

Para o autor, a produção do ato educativo tem dois sentidos. O primeiro é a relação direta entre educador e educando. Este é o mais explícito, uma vez que, em sala de aula o professor transmite e os alunos se apropriam dos conhecimentos gerados pela humanidade histórica. $\bigcirc$ segundo sentido - a humanização - não é tão explícita, mas de igual modo se faz presente. Tanto a educação quanto a humanização são o resultado mais direto do trabalho educativo. A existência de outros resultados seria decorrente deste processo (DUARTE, 2008).

A educação escolar é um espaço privilegiado para a (re)produção constante da condição humanizada. É nesse espaço que o trabalho educativo pode (re)produzir a humanidade em cada sujeito, 
ou seja, o trabalho educativo (re)produz o saber sobre a natureza e sobre a própria cultura humana, sempre atualizando-os de acordo com o momento sócio-histórico a que se insere. No entanto, essa produção não é um produto materializado. Ela se caracteriza como uma produção não material, que é produzida e consumida quase que instantaneamente no processo pedagógico - a aula - a qual relaciona estreitamente docente e estudante (SAVIANI, 20 I I).

É por meio do trabalho educativo que se garante - ou deveria se garantir - a especificidade da escola que, segundo Saviani (201 I, p. 84), "tem uma função especificamente educativa, propriamente pedagógica, ligada à questão do conhecimento". O autor menciona ainda (201 I, p. 84) que é preciso "resgatar a importância da escola e reorganizar o trabalho educativo, levando em conta o problema do saber sistematizado, a partir do qual se define a especificidade da educação escolar".

Por fim, Duarte (2008) menciona que, para a identificação dos elementos culturais indispensáveis à humanização do indivíduo, o trabalho educativo assume um duplo posicionamento. $\bigcirc$ primeiro está relacionado à cultura humana, em relação às objetivações historicamente produzidas. Nesse sentido, o trabalho educativo possibilita ao indivíduo a transmissão da cultura humana. $\bigcirc$ segundo posicionamento diz respeito ao processo de formação dos indivíduos para que a sua humanização seja possível. Como dito anteriormente, humanização é o ato de produzir a historicidade em cada indivíduo. É devido a tais posicionamentos que o trabalho docente, no contexto escolar, não pode ser esvaziado. Negar a transmissão do conhecimento clássico aos estudantes inviabiliza ou dificulta que eles se humanizem.

\section{CONHECIMENTOS CLÁSSICOS}

De forma preliminar, os conhecimentos clássicos são o que há de mais desenvolvido no conjunto dos conhecimentos produzidos ao longo da história da humanidade. A transmissão ${ }^{3}$ desses conhecimentos deve ocorrer no contexto escolar por meio do trabalho educativo, nos diferentes componentes curriculares.

De acordo com Saviani (20l I), nós - indivíduos da espécie humana - precisamos em um primeiro momento identificar os elementos culturais necessários para nos tornarmos cada vez mais humanizados. Após essa identificação, o segundo momento seria o de assimilação ${ }^{4}$ (apropriação) desses elementos. No entanto, os dois momentos só são possíveis se, ao mesmo tempo, formas mais adequadas para atingi-los

\footnotetext{
${ }^{3}$ A 'transmissão' não se refere a uma simples transferência de conteúdos decorados e descontextualizados, característica da pedagogia tradicional; muito menos se aproxima de ideias cognitivistas. Transmissão, para a PHC, é um conceito que deve ser sempre compreendido conjuntamente com a ideia de apropriação do conhecimento, pois este é produzido ao longo da história humana e, só são superados e desenvolvidos porque são (re)transmitidos e (re)apropriados ao longo das gerações.

${ }^{4}$ Atualmente, a PHC utiliza preferencialmente o termo 'apropriação', em função de expressar melhor a ação realizada no processo de transmissão e apropriação do saber escolar, e porque se distancia de pressupostos piagetianos. Mantivemos aqui a palavra 'assimilação' por ser o termo que Saviani (201 I) utiliza no texto original de 1991.
} 
forem descobertas através do desenvolvimento do trabalho pedagógico. Conforme Saviani (20 I I, p. I 3), é através da "organização dos meios (conteúdos, espaço, tempo, procedimentos) que é possível que progressivamente, cada indivíduo singular realize em si, na forma de segunda natureza, a humanidade produzida coletiva e historicamente".

Considerando a organização dos meios, um critério útil para seleção dos conteúdos escolares enquanto objeto de trabalho da escola deve partir sempre dos conhecimentos clássicos (SAVIANI, 20I I). Nesse sentido, cabe entender como a PHC compreende de forma mais aprofundada este conceito. Saviani (20II) define 'clássico' como tudo aquilo que se firmou como essencial, que resistiu aos desafios do tempo, mantendo-se válido ao extrapolar e superar o momento da sua produção. É, portanto, permanente.

Por exemplo: para Liporini (20 I 6), o conjunto de conteúdos relacionados às áreas de Sistemática e Filogenética são considerados conhecimentos clássicos no ensino de Biologia. A autora embasa sua afirmação em uma revisão histórica sobre esses campos de conhecimento e exemplifica como conteúdos clássicos as árvores filogenéticas, o conceito de espécie e os critérios de classificação e caracterização dos cinco reinos biológicos. Liporini (2016) acredita que esses conhecimentos concorrem para uma abordagem hierárquica, organizada e não fragmentada para se ensinar Biologia.

Assim, destacamos que o conceito de 'clássico' é diferente de 'tradicional', e não pode ser confundido ou se opor ao moderno e atual. Saviani (20l I) afirma que 'tradicional' se relaciona ao passado, sendo considerado ultrapassado. As máximas possibilidades do desenvolvimento humano, até o presente momento, determinam o clássico como produto de um desenvolvimento histórico e contraditório. Esta contradição está expressa, por exemplo, nos conceitos de humanização e alienação no processo de desenvolvimento humano (FERREIRA, 2017; GIARDINETTO, 20I0).

Mas quais seriam os 'conhecimentos clássicos'? Quais seriam os elementos culturais necessários para a humanização? Para responder a estas perguntas, é necessária a compreensão de alguns conceitos que serão apresentados a seguir.

As formas mais desenvolvidas de expressão dos saberes produzidos historicamente pelos humanos são os saberes objetivos. $O$ saber objetivo tem o status de saber universal, uma vez que a sua universalidade está diretamente ligada à questão da objetividade. Falar que o saber é universal é dizer que ele é objetivo, ou como diz Saviani, (2011, p. 50), "que expressa as leis que regem a existência de determinado fenômeno, trata-se de algo cuja validade é universal. E isto se aplica tanto a fenômenos naturais como sociais".

O saber objetivo relaciona-se com as 'objetivações genéricas para si', as quais expressam as máximas possibilidades de desenvolvimento humanizado. São essas objetivações genéricas que delimitam o conjunto dos 'conhecimentos clássicos'. Para compreender quais são esses conhecimentos, também é 
importante definir duas das categorias básicas do processo de formação do indivíduo: a 'apropriação' e a 'objetivação'. Segundo Duarte (2013, pp. 8-9), ambas "expressam a dinâmica do processo pelo qual o ser humano se autoconstrói ao longo da história”. Em relação especificamente à 'objetivação', o autor (idem) ressalta que a mesma "pode ser entendida como o processo por intermédio do qual a atividade do sujeito se transforma em propriedades do objeto". Contudo, o objeto resultante não é sempre material. Dois exemplos para ilustrar esse conceito são citados por Duarte (20।3): a aula ministrada por um professor e uma mesa fabricada por um marceneiro.

Já a categoria 'apropriação' refere-se ao processo inverso da objetivação, ou seja, a transferência da atividade do objeto para o sujeito. Nas palavras do autor (2013, pp. 9-10), "quando alguém aprende a usar uma ferramenta, está se apropriando da atividade social acumulada no objeto". Um exemplo é a apropriação da linguagem, resultante das apropriações das atividades histórica e social de comunicação que foram acumuladas nela.

As objetivações genéricas podem ser classificadas em 'objetivações genéricas em si' e 'objetivações genéricas para si'. As primeiras são próprias da vida cotidiana, como a linguagem, os costumes e os utensílios. Já as segundas não fazem parte da vida cotidiana, sendo representadas pela Ciência, Filosofia, Política, Ética, Moral e pelas Artes. Todas são produtos resultantes do processo histórico de objetivação (DUARTE, 2013).

A Ciência é uma objetivação genérica para si essencialmente humanizadora. Contudo, no modo como tem sido conduzida, segundo Duarte (2013, p. 12), "tem tornado possível a máxima alienação que é a autodestruição da humanidade". Apesar disso, é da Ciência que deriva o conceito de saber elaborado que nos interessa expor. A Ciência tem características próprias: é sistemática, metódica e replicável. $\bigcirc$ saber elaborado que dela deriva também possui tais características. É também por meio desse saber que o indivíduo pode se instrumentalizar para compreender criticamente as contradições da sociedade, as quais estão baseadas nas desigualdades econômica, cultural e política (GIARDINETTO, 20 I0).

Portanto, todo 'saber elaborado' é um 'saber objetivo'. Mas nem todo 'saber objetivo' é 'saber elaborado', pois há outras formas de saber que também são objetivos, mas que não derivam da Ciência, como o artístico, por exemplo. Consequentemente, 'conhecimento clássico' (ou 'saber elaborado') é 'saber objetivo'. Ele é produzido a partir das objetivações genéricas para si, e são esses os conhecimentos que devem ser transformados em saberes escolares pelo processo pedagógico. Como afirmam Lavoura; Martins (2017, p. 534), em nossa sociedade, a mediação da escola é necessária porque:

[...] a atividade de aprendizagem possibilita aos alunos a apropriação dos conteúdos escolares necessários para o conhecimento da realidade (dimensão epistemológica) e, ao mesmo tempo, a apreensão dos nexos e relações que lhe permitem compreender e explicar o que essa realidade realmente é (dimensão ontológica). 
Ademais, para a PHC, segundo Saviani (201 I, pp. 8-9), a tarefa da educação escolar implica justamente em:

\begin{abstract}
a) identificação das formas mais desenvolvidas em que se expressa o saber objetivo produzido historicamente, reconhecendo as condições de sua produção e compreendendo as suas principais manifestações, bem como as tendências atuais de transformação; b) conversão do saber objetivo em saber escolar, de modo que se torne assimilável pelos alunos no espaço e tempo escolares. c) provimento dos meios necessários para que os alunos não apenas assimilem o saber objetivo enquanto resultado, mas apreendam o processo de sua produção, bem como as tendências de sua transformação.
\end{abstract}

Ao converter o saber objetivo em saberes escolares, estes passam a ter importância fundamental. Saviani (20 I 2, p. 64) menciona que o acesso ao saber deve ser igual para todos, bem como sua distribuição também deve ser igualitária. $\bigcirc$ autor afirma também que o caráter revolucionário e histórico dos conteúdos culturais deriva de sua historicidade, de modo que "a transformação da igualdade formal em igualdade real está associada à transformação dos conteúdos formais, fixos e abstratos, em conteúdos reais, dinâmicos e concretos".

A PHC, revolucionária, conforme o referido autor (idem, p. 65), não secundariza "os conhecimentos. descuidando de sua transmissão. Ao contrário, considera a difusão de conteúdos, vivos e atualizados, uma das tarefas primordiais do processo educativo em geral e da escola em particular".

Ainda sobre a importância dos saberes escolares, representados pelos conteúdos, Saviani (2012, p. 55) traz algumas considerações:

[...] os conteúdos são fundamentais e, sem conteúdos relevantes, conteúdos significativos, a aprendizagem deixa de existir, ela se transforma num arremedo, ela se transforma numa farsa. Parece-me, pois, fundamental que se entenda isso e que, no interior da escola, nós atuemos segundo essa máxima: a prioridade de conteúdos, que é a única forma de lutar contra a farsa do ensino. Por que esses conteúdos são prioritários? Justamente porque o domínio da cultura constitui instrumento indispensável para a participação política das massas. Se os membros das camadas populares não dominam os conteúdos culturais, eles não podem fazer valer os seus interesses, porque ficam desarmados contra os dominadores, que se servem exatamente desses conteúdos culturais para legitimar e consolidar a sua dominação. Eu costumo, às vezes, enunciar isso da seguinte forma: o dominado não se liberta se ele não vier a dominar aquilo que os dominantes dominam. Então dominar o que os dominantes dominam é condição de libertação. (destaque nosso).

A dominação acima citada relaciona-se à dominação estrutural na sociedade capitalista, resultado da alienação e da exploração do ser humano pelo homem. Relação esSa que, para ser superada, não pode prescindir da apropriação do saber pela camada oprimida da população.

Conforme Saviani (20 I I), os conhecimentos que deveriam ser transmitidos pela escola são aqueles produzidos de forma metódica, científica. Portanto, não se trata de conhecimentos espontâneos. São conhecimentos de caráter universal que se tornaram fundamentais para a garantia da transformação da realidade natural em realidade humanizada (GIARDINETTO, 20I0). 
Os saberes escolares, ao possuírem a universalidade como caráter, seguem as leis orientadoras dos fenômenos naturais e sociais. Assim, sua validade ultrapassa e não está condicionada a qualquer interesse, seja este particular de pessoa, de classe, de lugar ou de tempo (SAVIANI, 20 I I). No entanto, por vivermos numa sociedade de classes cujos interesses são opostos e cuja instrução generalizada das massas é contrária aos interesses da estratificação de classes, a escola (pública) e a educação que cabe a ela ofertar são cada vez mais desvalorizadas.

A educação escolar para a PHC é produto da mediação entre as objetivações genéricas em si e as objetivações genéricas para si. À escola competiria a transmissão e a apropriação das objetivações genéricas para si (GIARDINETTO, 20 I0). A educação escolar é uma atividade mediadora no interior da prática social global, isto porque, conforme Lavoura; Meireles (20।3, p. 100) possibilita "no processo de formação dos indivíduos, a ultrapassagem da esfera da vida cotidiana para as esferas não-cotidianas da prática social, por meio do desenvolvimento de necessidades cada vez mais elevadas, as quais não podem ser satisfeitas no plano da imediaticidade do cotidiano".

Contrariamente à teorização da PHC, a educação escolar tem sido encarada como uma atividade cotidiana, associada às atividades do dia a dia dos indivíduos. Ao se naturalizar o dia a dia escolar como atividades da vida cotidiana, a atividade de ensino torna-se uma atividade espontânea que, segundo Lavoura e Meireles (2013, p. I02) é "demarcada pela ausência da reflexão e da criticidade, não possibilitando aos indivíduos o alcance das objetivações genéricas para si". Portanto, o papel da educação escolar - bem como do trabalho educativo - na formação do indivíduo é, justamente, o de mediação entre as esferas da vida cotidiana e não cotidiana. Isso implica o acesso e a apropriação dos conhecimentos clássicos pelos estudantes na escola.

Para Taffarel (20। 3, pp. 23-24), ao cumprir esse papel, a escola realiza então sua função social que é:

[...] elevar a capacidade teórica dos estudantes, o que passa pelo desenvolvimento da capacidade científica, a atitude científica. Passa pela valorização da aquisição, pelo estudante, dos conhecimentos científicos, artísticos e filosóficos em sua forma mais desenvolvida, o que implica no desenvolvimento de funções psicológicas superiores [... . . A escola é o local principal onde esta função social, cara a formação da classe trabalhadora, deve ser materializada. A escola é, portanto, o local de universalização da cultura enquanto possibilidade concretamente existente.

Para Saviani (2012, pp. 69-70), a PHC é uma pedagogia articulada aos interesses populares, que valoriza a escola e que não será indiferente aos acontecimentos do seu interior. A PHC:

[...] estará empenhada em que a escola funcione bem; portanto, estará interessada em métodos de ensino eficazes. Tais métodos se situarão para além dos métodos tradicionais e novos, superando por incorporação as contribuições de uns e de outros. Portanto, serão métodos que estimularão a atividade e iniciativa dos alunos sem abrir mão, porém, da iniciativa do professor; favorecerão o diálogo dos alunos entre si e com o professor, mas sem deixar de valorizar o diálogo com a cultura acumulada historicamente; levarão em conta os interesses dos alunos, os ritmos de aprendizagem e o desenvolvimento psicológico, mas sem perder de vista a sistematização lógica 
dos conhecimentos, sua ordenação e gradação para efeitos do processo de transmissãoassimilação dos conteúdos cognitivos.

É nessa escola que o docente tem papel indispensável quanto à transmissão dos 'conhecimentos clássicos', uma vez que é quem medeia e viabiliza a apreensão dos conhecimentos. Nesse sentido, é a partir do 'trabalho educativo' que os 'conhecimentos clássicos' poderão ser desenvolvidos pelo docente e apreendidos pelos alunos na escola.

\section{CONHECIMENTOS CLÁSSICOS E TRABALHO EDUCATIVO NO ENSINO CRÍTICO DE CIÊNCIAS}

O que nos interessa nesta seção é discutir sobre as articulações possíveis entre o ensino de Ciências (EC), os 'conhecimentos clássicos' das Ciências e da Biologia e o 'trabalho educativo'. A ideia é indicar como esses dois princípios podem se concatenar no ensino dessas disciplinas para tornar mais crítico o processo de transmissão e apropriação no espaço escolar. Para tanto, iniciaremos caracterizando a área de EC e depois indicaremos quais são os seus objetivos, a partir de documentos que balizam o currículo de Ciências no Brasil. Apresentaremos, também, pesquisas que indicam conteúdos clássicos das disciplinas Ciências e Biologia, dialogando em favor da sua socialização pela escola.

O EC é um campo consolidado do conhecimento e possui caráter interdisciplinar, uma vez que se apropriou de saberes de outras áreas, tendo-as como quadro de referência. A Figura I mostra as intersecções de diferentes disciplinas para a consolidação do EC.

Figura I - Caráter interdisciplinar da Educação em Ciências

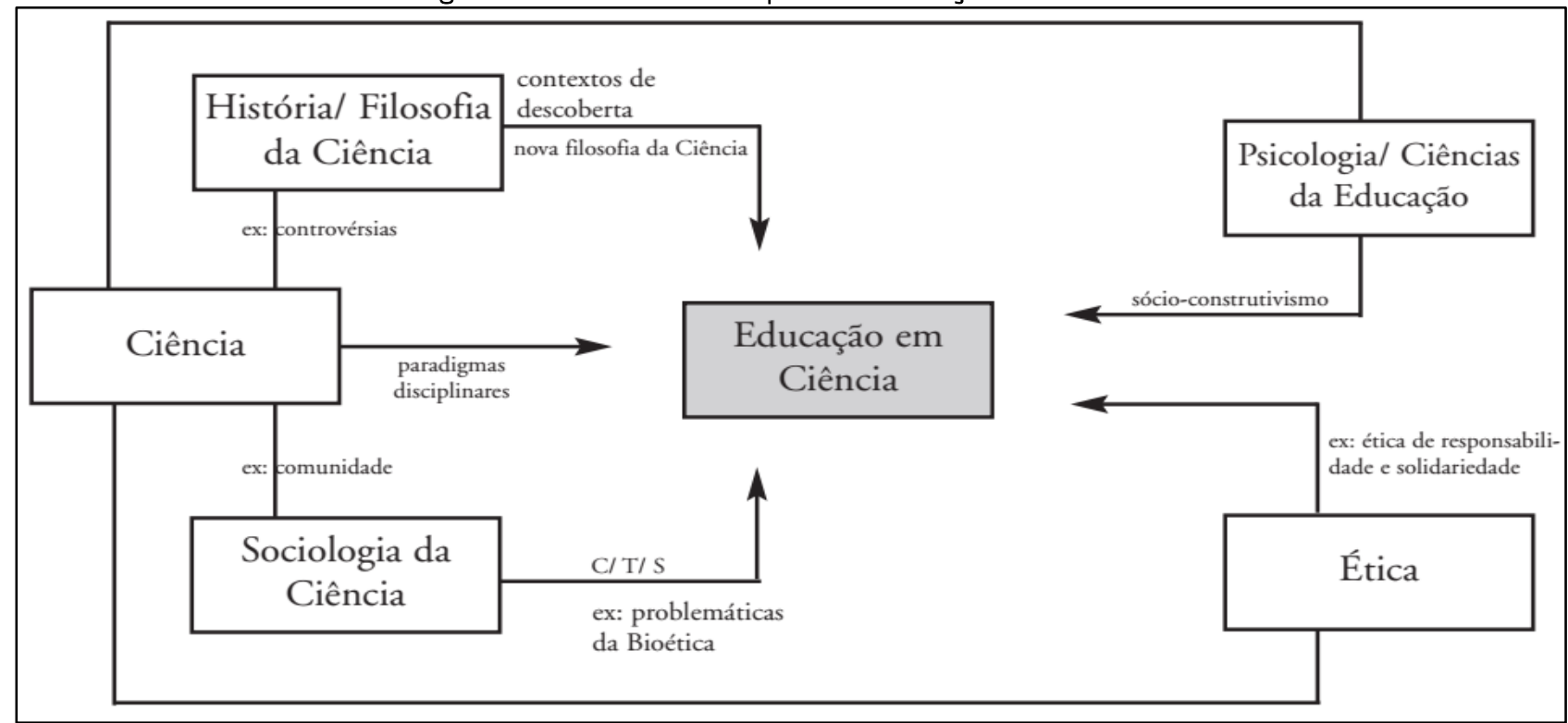

Fonte: Cachapuz, Praia e Jorge (2004, p. 365). 
Portanto, o quadro teórico final que constitui o EC é resultante das apropriações de outras disciplinas, como as Ciências da Educação, a Sociologia da Ciência e a Psicologia. Contudo, se diferencia dessas, à medida que passa por um novo processo de reelaboração, conduzindo ao surgimento de uma nova área. Devido a sua consolidação enquanto campo de conhecimento, os seus objetivos não são os mesmos das disciplinas das quais se derivou.

Nesse sentido, autores como Reid e Hodson (1993) acreditam que a educação científica (ou o EC) deve contribuir para se instaurar uma cultura científica. Para tanto, há elementos essenciais para a compreensão da Ciência que precisam previamente ser apropriados. Todo esse movimento de instauração de uma cultura científica deve preconizar os fatos, conceitos e teorias. Para os autores, ao se ensinar Ciências, é preciso que as pessoas se familiarizem com os seus procedimentos, instrumentos e técnicas para que possam aplicar o conhecimento aprendido em situações reais de resolução de problemas.

A Ciência precisa ser discutida com base nos aspectos sociais, econômicos, políticos, éticos e morais. Por fim, os autores ainda enfatizam a importância de se trabalhar com a história e o desenvolvimento da Ciência e Tecnologia, do estudo sobre a natureza da Ciência e da prática científica, considerando as suas dimensões filosóficas e sociológicas centradas nos métodos científicos (REID; HODSON, 1993).

A ideia de que a Ciência deve contribuir para gerar conhecimentos com aplicação prática direta e imediata, sendo, portanto, utilitarista é característica do modo de produção capitalista, como apontado por Duarte (20|5). Não negamos a importância da utilização imediata do conhecimento científico e tecnológico para a solução de problemas na vida prática da humanidade. Contudo, ao restringir o seu uso à imediaticidade, fica inviabilizada a formação de uma concepção de mundo materialista histórico dialética. Duarte (20I5) ressalta que isso não significa que haverá o ensino da teoria materialista histórica dialética em sala de aula. $\bigcirc$ autor afirma que a transmissão dos conteúdos escolares possibilita as bases para a formação de concepção de mundo nessa perspectiva.

Para Krasilchick (2000), os objetivos maiores do ensino de Ciências devem incluir, necessariamente, a apropriação e a aquisição do conhecimento científico pela população. Para a autora, a Ciência deve ser compreendida como um empreendimento social.

No entanto, existem documentos que regem os objetivos e, consequentemente, o currículo para o ensino de Ciências e Biologia. Em função disso, é important,e ainda que de forma breve, apontar quais são esses objetivos e apresentar alguns documentos norteadores do currículo em âmbito nacional, como os Parâmetros Curriculares Nacionais (PCN) e a Base Nacional Comum Curricular (BNCC).

Segundo os PCN (BRASIL, I998, p. 32), o objetivo de se ensinar Ciências Naturais no ensino fundamental é desenvolver no aluno desenvolver "competências que the permitam compreender o 
mundo e atuar como indivíduo e como cidadão, utilizando conhecimentos de natureza científica e tecnológica".

Os PCN apresentam ainda, eixos temáticos que buscam articular os conceitos, procedimentos, atitudes e valores que farão parte de todos os ciclos da escolaridade em Ciências. Os eixos são: Terra e Universo; Vida e Ambiente; Ser humano e Saúde; e Tecnologia e Sociedade. Para a escolha dos conteúdos relativos a esses eixos, os PCN estabelecem três critérios, a saber:

- $\quad$ os conteúdos devem favorecer a construção, pelos estudantes, de uma visão de mundo como um todo formado por elementos inter-relacionados, entre os quais o ser humano, agente de transformação. Devem promover as relações entre diferentes fenômenos naturais e objetos da tecnologia, entre si e reciprocamente, possibilitando a percepção de um mundo em transformação e sua explicação científica permanentemente reelaborada;

- os conteúdos devem ser relevantes do ponto de vista social, cultural e científico, permitindo ao estudante compreender, em seu cotidiano, as relações entre o ser humano e a natureza mediadas pela tecnologia, superando interpretações ingênuas sobre a realidade à sua volta. Os temas transversais apontam conteúdos particularmente apropriados para isso;

- $\quad$ os conteúdos devem se constituir em fatos, conceitos, procedimentos, atitudes e valores a serem promovidos de forma compatível com as possibilidades e necessidades de aprendizagem do estudante, de maneira que ele possa operar com tais conteúdos e avançar efetivamente nos seus conhecimentos (BRASIL, 1998, p. 35).

Os Parâmetros Curriculares Nacionais do Ensino Médio (PCNEM) possuem a mesma finalidade que os PCN. Para a área de Ciências, incluindo a Biologia, a Física e a Química, os alunos precisam "compreender as Ciências da Natureza como construções humanas e a relação entre conhecimento científico tecnológico e a vida social e produtiva" (BRASIL, PCNEM, 1998, p. II).

Embora os PCN destaquem os pontos orientadores para a seleção de conteúdos, o documento não especifica quais são eles. Isso ocorre porque, para os PCN, o enfoque não é a aprendizagem de conteúdos propriamente dita, mas sim o desenvolvimento de determinadas competências, como citado anteriormente. Nessa questão, há um ponto de fundamental discordância para a PHC. Saviani (20 I I) já apontou que o critério para a seleção dos conteúdos deve partir sempre dos 'conhecimentos clássicos'. Isso porque estes saberes representam o máximo desenvolvimento da cultura humana e sua aprendizagem pode contribuir para o desenvolvimento de diversas funções psicológicas superiores, como a atenção voluntária, a memória lógica e a abstração (MALANCHEN, 2016).

Na análise das reformas do currículo de Ciências no Brasil, Krasilchick (2000) alertou que o currículo pautado no desenvolvimento de competências e habilidades não forma adequadamente os alunos para correlacionarem as disciplinas escolares com a atividade científica e tecnológica; de igual modo não as relacionam com os problemas sociais contemporâneos.

Outro documento orientador dos currículos no Brasil é a BNCC (BRASIL, 20I8). Esta apresenta dez competências gerais que se inter-relacionam e perpassam todos os componentes curriculares da Educação Básica. A Base apresenta também as aprendizagens essenciais a serem asseguradas para orientar o EC sob três unidades temáticas: "Matéria e Energia”, "Vida e Evolução" e “Terra e Universo". Ela aponta, 
de igual modo, oito competências a serem trabalhadas na área das Ciências da Natureza do ensino

fundamental, a saber:

I. compreender as ciências como empreendimento humano, reconhecendo que o conhecimento científico é provisório, cultural e histórico;

2. compreender conceitos fundamentais e estruturas explicativas das Ciências da Natureza, bem como dominar processos, práticas e procedimentos da investigação científica, de modo a sentir segurança no debate de questões científicas, tecnológicas e socioambientais e do mundo do trabalho;

3. analisar, compreender e explicar características, fenômenos e processos relativos ao mundo natural, tecnológico e social, como também às relações que se estabelecem entre eles, exercitando a curiosidade para fazer perguntas e buscar respostas;

4. avaliar aplicações e implicações políticas, socioambientais e culturais da ciência e da tecnologia e propor alternativas aos desafios do mundo contemporâneo, incluindo aqueles relativos ao mundo do trabalho;

5. construir argumentos com base em dados, evidências e informações confiáveis e negociar e defender ideias e pontos de vista que respeitem e promovam a consciência socioambiental e o respeito a si próprio e ao outro, acolhendo e valorizando a diversidade de indivíduos e de grupos sociais, sem preconceitos de qualquer natureza.

6. utilizar diferentes linguagens e tecnologias digitais de informação e comunicação para se comunicar, acessar e disseminar informações, produzir conhecimentos e resolver problemas das Ciências da Natureza de forma crítica, significativa, reflexiva e ética.

7. conhecer, apreciar e cuidar de si, do seu corpo e bem-estar, compreendendo-se na adversidade humana, fazendo-se respeitar e respeitando o outro, recorrendo aos conhecimentos das Ciências da Natureza e suas tecnologias.

8. agir pessoal e coletivamente com respeito, autonomia, responsabilidade, flexibilidade, resiliência e determinação, recorrendo aos conhecimentos das Ciências da Natureza para tomar decisões frente a questões científico-tecnológicas e socioambientais e a respeito da saúde individual e coletiva, com base em princípios éticos, democráticos, sustentáveis e solidários (BRASIL, 20I8, p. 324).

No entanto, como apontado por Marsiglia e colaboradores (2017), os princípios da BNCC vêm atender aos interesses da classe empresarial, contribuindo para mais um episódio do esvaziamento da escola. Por focar nas "competências" e "habilidades" e não evidenciar os conteúdos escolares, o trabalho educativo e o ensinar, o documento coaduna com a perspectiva de formação do estudante (especialmente da escola pública) para atender as demandas do mercado de trabalho. Esse esvaziamento acaba por censurar a aquisição pelos estudantes do saber elaborado, contribuindo para dificultar ou impossibilitar a sua compreensão da realidade e a tentativa de transformação da mesma.

Descrevemos anteriormente critérios para a seleção dos conteúdos na perspectiva da PHC e dos documentos oficiais. Sendo assim, alguns autores da área do EC e Biologia apresentam critérios para a seleção de conteúdos. Carvalho, Nunes-Neto e El-Hani (20I I ) fazem-no na Biologia a partir dos conceitos estruturantes dessa componente curricular. Para tanto, o ponto de partida pode ser a divisão da Biologia nos ramos funcional e evolutivo. O primeiro tem caráter imediato, de causa próximas, pois acontecem num período de tempo curto. $\bigcirc$ segundo tem caráter histórico porque trabalha com questões cuja explicação só é dada por meio da evolução biológica. São duas ramificações da Biologia que, para os autores, devem ser trabalhadas concomitantemente no contexto escolar. Ambos os ramos, funcional e evolutivo, poderiam ser considerados conteúdos clássicos à medida que possibilitam aos estudantes a 
aprendizagem de forma mais integrada sobre o mundo vivo. Capacitam, de igual modo, o desenvolvimento para o exercício de uma cidadania consciente e responsável.

Apesar da discussão teórico-filosófica sobre as Ciências da Natureza ainda ser limitada sob a perspectiva marxista (PEREIRA, 2017), alguns trabalhos tecem proposições sobre quais seriam os conhecimentos clássicos das Ciências e/ou Biologia.

Beduschi (2018, p. 6l) menciona que o eixo unificador da Biologia é o conteúdo de evolução biológica, constituindo-se norteador desse componente curricular. $\bigcirc$ autor considera-০, ainda, como um 'conteúdo clássico', uma vez "que se configura como um objeto de estudo que ultrapassou os embates do tempo e das classes sociais, sendo hoje a base para a compreensão das ciências biológicas".

Rosa (2018) lança o mesmo olhar para a Teoria da Evolução. Segundo a autora, os elementos fundamentais do pensamento evolutivo Darwinista, sofisticados posteriormente por outros evolucionistas, evidenciam o seu potencial formador das bases da concepção materialista, histórica e dialética de natureza. Os conceitos relativos à evolução analisados, dentre outros, foram: organismo, população, espécie, seleção natural, adaptação. A autora ( 2018, p. 135) apresenta como 'clássicos' o pensamento evolutivo e os seus antecedentes "à medida que contribuem para a formação da concepção objetiva de mundo, porém, dotados de limites mais ou menos idealistas, metafísicos, formais". O avanço da Biologia e do pensamento darwiniano derrubaram pilares idealistas, teleológicos e metafísicos característicos do pensamento dos antecessores de Darwin.

Os conteúdos relativos à evolução, além de terem resistido ao tempo, sobrevivendo ao desenvolvimento de mais estudos e aos questionamentos científicos, contribuem - em longo prazo - para transformações de paradigmas sociais, bem como para uma maior compreensão dos processos biológicos relacionados ao próprio corpo e ao ambiente no qual os estudantes estão inseridos.

A transmissão e a apropriação dos conteúdos escolares, como por exemplo a Evolução, por meio dos conhecimentos clássicos, são consideradas o caminho para que estudantes e professores (trans)formem as suas concepções de mundo para a concepção materialista histórico dialética (DUARTE, 20 I5). Para o autor, ensinar Ciências, bem como outras disciplinas, é ensinar também concepções de mundo que a elas estão vinculadas, caracterizando assim o ato educativo.

Ao longo de toda a escolarização é possível a formação das bases para a difusão da concepção de mundo materialista histórico dialética. Duarte (20l5) defende essa formação pela escola em cada aluno, uma vez que visões de mundo não são formadas do nada ou apenas pelas experiências individuais do sujeito. Este herda da sociedade elementos que o fazem transformar a sua concepção de mundo, podendo reelaborá-la de modo ingênuo ou crítico.

Outros estudos na área de Ensino de Ciências e Biologia apontam como conhecimentos clássicos os conteúdos de Sistemática e Taxonomia, subáreas da Biologia. Liporini (2016) enfatiza que esses 
conteúdos integram a Biologia como campo do conhecimento. Essa integração é essencial e duradoura, pois permite a sistematização de outros conhecimentos biológicos (conceito de espécie e de árvore filogenética, por exemplo).

Rosa e Martins (2017) também assumem os conteúdos do sistema de classificação dos seres vivos - Taxonomia e da Sistemática filogenética - como conteúdos clássicos. As autoras tiveram por objetivo refletir sobre o ensino desses sistemas de classificação e o desenvolvimento da função psíquica do pensamento, tendo como enfoque o pensamento abstrato empírico e o pensamento abstrato teórico. A partir de uma pesquisa bibliográfica, as autoras mencionam que a Taxonomia se aproxima de uma ciência empírica (pensamento empírico) mais próxima da lógica formal, enquanto que a Sistemática se aproxima de uma ciência teórica (pensamento teórico) mais próxima da lógica dialética.

Na pesquisa de Campos (2017), a autora teve por objetivo compreender como se produzia concretamente uma prática pedagógica numa perspectiva da $\mathrm{PHC}$ no ensino de Biologia. $\mathrm{O}$ trabalho constituiu-se uma intervenção pedagógica realizada com uma turma de alunos do Ensino Médio. As atividades realizadas partiram dos 'conteúdos clássicos' de Taxonomia e Sistemática sob uma compreensão de mundo materialista histórico dialética. A sua intervenção didática teve por objetivo a transmissão dos conteúdos citados antes e, o estabelecimento entre os conteúdos e o saber da realidade. Campos (20 l 7) argumenta que é possível desenvolver uma prática pedagógica na perspectiva da $\mathrm{PHC}$ em qualquer disciplina, em qualquer conteúdo e em qualquer fase do desenvolvimento biológico. Contudo, o ensino de Biologia numa perspectiva histórica e dialética só é possível por meio da superação do enfoque essencialista, tipológico e metafísico dessa área, completa a autora.

No presente artigo, fez parte do nosso objetivo a discussão relacionada ao conteúdo na forma de conhecimentos clássicos, e, embora não tenhamos desenvolvido a questão relativa à forma, para a PHC ela também é importante. O professor medeia o conteúdo a ser ensinado e a forma sob a qual é ensinado. Para Duarte (20 I 5), o clássico em si mesmo é uma unidade entre conteúdo e forma, mas que pode ser ensinado sob diferentes formas, quando transformado em conteúdo escolar.

Não existe uma forma de se ensinar para a PHC, pois independente da estratégia, técnica ou procedimento didático a ser utilizado, quatro elementos devem ser avaliados: quem ensina; quem aprende; o que se ensina e em que condições a atividade educativa se realiza. Para a PHC há sempre algo a ser ensinado, cabendo ao professor o ato de ensinar - o 'trabalho educativo'. Esse pressuposto se relaciona segundo Duarte (2015, p. 18) ao pressuposto de que "há conteúdos científicos, artísticos e filosóficos que se constituem em valores conquistados pelo desenvolvimento histórico do gênero humano e são representativos".

O trabalho de Santos (2005) intitulado "Ensino de ciências: abordagem histórico-crítica" indica caminhos e possibilidades para o desenvolvimento didático-pedagógico numa perspectiva histórico-crítica 
aliada ao EC. Abordagem semelhante ao que foi desenvolvido na pesquisa de Geraldo (2005) intitulada "Didática de Ciências e de Biologia na perspectiva da pedagogia histórico-crítica".

Como mencionado anteriormente, Santos (2005) destaca e analisa as três tendências de base construtivista que dominam o EC. Na primeira perspectiva que parte da História da Ciência, o autor indica que muitos trabalhos se limitam a apresentar, a partir de levantamentos em textos históricos originais, a história do conceito em estudo, o que permite realizar essa reconstrução. No entanto, de acordo com Santos (2005), não consideram a história das lutas e demandas socioeconômicas que levaram os homens da Ciência a trabalhar determinados temas. Pela falta de material didático sob essa concepção, o autor defende a produção de materiais que reconstruam as lutas sociais por trás dos conceitos científicos.

Na segunda perspectiva, o cotidiano deve ser o norte do ensino e da aprendizagem de Biologia, Física e Química. Aqui se considera cotidiano aquilo que cerca a vida diária do sujeito. No entanto, Santos (20 I 5) afirma que prender-se a essa interpretação de cotidiano é cair em uma concepção reducionista da Ciência. É justamente isso que o EC precisa superar para evitar se transformar em pseudoensino ou, como mencionado antes, promover o esvaziamento do ensino. Santos (2005) acredita que a escola existe para que os alunos se distanciem desse cotidiano, apropriando-se do saber elaborado. $\bigcirc$ ato de educar possibilita a superação do cotidiano e de todas as suas limitações. Ao retornar para o cotidiano, há possibilidade de compreendê-lo em suas mediações.

Por fim, a terceira perspectiva analisada por Santos (20I5) compreende que o ensino de Ciências por meio da experimentação é importante para evidenciar o caráter da construção do conhecimento científico. No entanto, o autor assevera que, muitas vezes, perde-se o sentido dessa construção, quando há desvinculação entre a teoria e a experimentação ou se esta não estiver associada à realidade socioeconômica e à construção de teorias.

A análise de Santos (2005) sobre as tendências do EC destaca sua criticidade em relação ao modo pelo qual o EC vem sendo conduzido no Brasil. Não é demais realçar que é sob o ideário construtivista que o currículo do EC se assenta.

Geraldo (2006) propôs uma teoria da Didática para o ensino de Ciências e Biologia numa perspectiva histórico-crítica e na Didática Geral. $\bigcirc$ autor elaborou um conjunto de quinze princípios metodológicos para o ensino dessas disciplinas que servem como critério e orientações para a atividade docente. A partir do método dialético investigativo, os quinze princípios indicados pelo autor foram articulados aos elementos fundamentais do processo didático escolar, como os conteúdos, os objetivos, os métodos, dentre outros.

Os trabalhos de Santos (2005) e Geraldo (2006) indicam tentativas de elaboração de um ensino e de uma didática para o ensino de Ciências e Biologia pautado na PHC. Os princípios 'conhecimento 
clássico' e 'trabalho educativo' são inerentes a uma didática que pensa a educação como forma de humanização dos indivíduos e de sua conscientização quanto à luta de classes.

Ao assumir a PHC como teoria educacional, compreendemos que esta se apoia no materialismo histórico dialético. Isso significa que essa teoria assume que as disputas de classes da sociedade capitalista também se manifestam na escola, na forma de luta pela socialização do saber sistematizado.

Em função de toda a discussão e posicionamento que buscamos elaborar até aqui, enfatizamos que o ensino de Ciências, por meio do 'trabalho educativo', só é possível se os 'conhecimentos clássicos' forem socializados. Essa ação é uma condição para que o ensino crítico de Ciências e Biologia aconteça.

\section{CONSIDERAÇÕES FINAIS}

No intuito de contribuir com as discussões sobre o desenvolvimento do EC baseado na PHC, ensaiamos o objetivo de discutir sobre os princípios 'conhecimentos clássicos' e 'trabalho educativo'. Para tanto, recorremos a referenciais teóricos que assumem a PHC como teoria educacional que, dentre outros aspectos, contribue para a humanização e emancipação de estudantes diante de uma sociedade capitalista alienante. Procuramos também dialogar com textos de autores específicos da área de EC que não se vinculam à $\mathrm{PHC}$, mas que representam o pensamento hegemônico no EC.

A PHC defende a educação escolar por meio da transmissão e apropriação do saber elaborado. Enfatiza e diferencia esse saber do saber cotidiano de senso comum, sem negar a importância da aprendizagem de outras formas de conhecimento. Para a PHC, a especificidade da escola é justamente esse processo ocorrendo por meio do 'trabalho educativo'.

O EC está embasado nos pressupostos construtivistas, sendo assim, tem por finalidade desenvolver nos alunos competências e habilidades para que eles possam usar os conhecimentos adquiridos na resolução de problemas de modo imediato. Consideramos que essa concepção utilitarista do conhecimento científico deve ser superada. A restrição do EC a ela impede que estudantes elaborem uma visão de mundo histórica, crítica e dialética da Ciência e da sociedade.

Os conteúdos relativos à Evolução, Sistemática e Taxonomia filogenética foram considerados, a partir de pesquisas acadêmicas, como 'conhecimentos clássicos' do ensino de Ciências e Biologia. Tais estudos são pioneiros ao discutir e apresentar propostas de trabalho didático e embasamento teórico para o EC crítico, sob a visão da PHC.

Apontamos, ao longo do texto, as possíveis articulações entre os princípios 'trabalho educativo', 'conhecimentos clássicos' e o EC. Os trabalhos de Santos (2005) e Geraldo (2006) trazem direcionamentos iniciais para a compreensão de um ensino de Ciências e Biologia sob a perspectiva crítica. Não foi nossa intenção elaborar uma lista exaustiva de conteúdos clássicos ou apontar uma metodologia 
para o ensino com perspectiva histórico-crítica, mas sim argumentar que é possível desenvolver o ensino de Ciências e Biologia de forma crítica, valorizando o conteúdo científico e biológico, sem perder as conexões com a realidade concreta.

\section{REFERÊNCIAS}

BATISTA, E. L.; LIMA, M. R. A pedagogia histórico-crítica como teoria pedagógica transformadora: da consciência filosófica à prática revolucionária. In: MARSIGLIA, A. C. G.; BATISTA, E. L. (org.). Pedagogia Histórico-crítica: desafios e perspectivas para uma educação transformadora. Campinas: Autores Associados, 2012.

BEDUSCHI, R. S. O ensino de evolução biológica sob o olhar da Pedagogia Histórico Crítica: em busca das significações dos professores de Biologia. 20 18. 87 f. Dissertação (Mestrado em Educação para a Ciência) - Faculdade de Ciências, Universidade Estadual Paulista, Bauru, 2018.

BRASIL. Ministério da Educação. Secretaria da Educação Básica. Base nacional comum curricular. Brasília, DF, 20 18. Disponível em: http://basenacionalcomum.mec.gov.br/wpcontent/uploads/2018/I2/BNCC_19dez2018_site.pdf. Acesso em: 19 jan. 2019.

BRASIL. Secretaria de Educação Fundamental. Parâmetros curriculares nacionais: Ciências Naturais. Brasília: MEC / SEF, 1998. 138 p. Disponível em: http://portal.mec.gov.br/seb/arquivos/pdf/ciencias.pdf. Acesso em 17 jan. 2019.

CACHAPUZ, A.; PRAIA, J.; JORGE, M. Da educação em Ciências às orientações para o ensino das Ciências: um repensar epistemológico. Ciência \& Educação, Bauru, v. 10, n. 3, p. 363-38I , 2004.

CAMPOS, R. S. P. A perspectiva Histórico-Crítica e a prática docente de ensino de Biologia. 2017. I8I f. Tese (Doutorado em Educação para a Ciência) - Faculdade de Ciências, Universidade Estadual Paulista, Bauru, 2017.

CARVALHO, I. N.; NUNES-NETO, N. F.; EL-HANI, C. N. Como selecionar conteúdos de Biologia para o Ensino Médio? Revista de Educação, Ciências e Matemática, Rio de Janeiro, v. I, n. I , p. 67-I00, 2011 .

DUARTE, N. A individualidade para-si: contribuições a uma teoria histórico-social da formação do indivíduo. 3. ed. Campinas: Autores Associados, 2013.

DUARTE, N. A importância da concepção de mundo para a educação escolar: porque a pedagogia histórico-crítica não endossa o silêncio de Wittgenstein. Germinal: Marxismo e Educação em Debate, Salvador, v. 7, n. I, p. 8-25, jun. 2015.

DUARTE, N. Sociedade do conhecimento ou sociedade das ilusões? Quatro ensaios crítico-dialéticos em filosofia da educação. Ia . reim. Campinas: Autores associados, 2008.

FERREIRA, C. G. O conceito de clássico na pedagogia histórico-crítica. In: JORNADA DO HISTEDBR: pedagogia histórico-crítica, educação e revolução: 100 anos da revolução russa, | 4, 20 I7, Foz do Iguaçu. Anais [...]. Foz do Iguaçu: Unioeste, 20 17. p. I - I I. Disponível em: http://midas.unioeste.br/sgev/eventos/HISTEDBR/anais. Acesso em: 12 dez. 2018. 
GERALDO, A. C. H. Didática de Ciências e de Biologia na perspectiva da pedagogia Histórico-Crítica. 2006. 20 I f. Tese (Doutorado em Educação para a Ciência) - Faculdade de Ciências, Universidade Estadual Paulista, Bauru, 2006.

GIARDINETTO, J. R. O Conceito de Saber Escolar "Clássico" em Dermeval Saviani: implicações para a Educação Matemática. Boletim de Educação Matemática, Rio Claro, v. 23, n. 36, p. 753-773, ago. 2010. Disponível em: http://www.redalyc.org/pdf/29|2/29|2219050 I0.pdf. Acesso em: 12 dez. 2018.

KRASILCHIK, M. Reformas e Realidade: o caso do ensino de Ciências. São Paulo em Perspectiva, v. I4, n. I, p. 85-93, 2000.

LAVOURA, T. N.; MARSIGLIA, A. C. G. A pedagogia histórico-crítica e a defesa da transmissão do saber elaborado: apontamentos acerca do método pedagógico. PERSPECTIVA, Florianópolis, v. 33, n. I , p. 345-376, jan./abr. 2015.

LAVOURA, T. N.; MARTINS, L. M. A dialética do ensino e da aprendizagem na atividade pedagógica histórico-crítica. Interface, Botucatu, v. 21, n. 62, p. 531-54I, set. 2017. Disponível em

http://www.scielo.br/scielo.php?script=sci arttext\&pid=S| $4 \mid 4$ -

3283201700030053 I \&lng=pt\&nrm=iso. Acesso em I 6 jan. 2019.

LAVOURA, T. N.; MEIRELES, A. C. O "Aprender a aprender" pedagógico e a reprodução da alienação na educação escolar. In: DOS SANTOS, C. F. (org.). Crítica ao esvaziamento da educação escolar. Salvador: EDUNEB, 2013. p. 83-II3.

LESSA, S.; TONET, I. Introdução à filosofia de Marx. 2. ed. Editora Expressão Popular: São Paulo, 201 I . MALANCHEN, J. Cultura, Conhecimento e currículo: contribuições da pedagogia histórico-crítica. Campinas: Autores Associados, 2016.

MARSIGLIA, A. N. G. PINA, L. D.; MACHADO, V. O.; LIMA, M. A Base Nacional Comum Curricular: um novo episódio do esvaziamento da escola no Brasil. Germinal: Marxismo e Educação em Debate, Salvador, v. 9, n. I, p. 107-121, abr. 2017.

MATTHEWS, M. Construtivismo e o ensino de Ciências: uma avaliação. Cad. Cat. Ens. Fís., v. 17, n. 3, p. 270-294, dez. 2000.

LIPORINI, T. Q. O ensino de sistemática e taxonomia biológica no ensino médio da rede estadual no município de São Carlos, SP. 2016. 86 f. Dissertação (Mestrado em Educação para a Ciência) Faculdade de Ciências, Universidade Estadual Paulista, Bauru, 2016.

PEREIRA, L. M. Os sentidos atribuídos por professores de Biologia à função social de seu trabalho. 2017. 26 I f. Dissertação (Mestrado em Educação para a Ciência) - Faculdade de Ciências, Universidade Estadual Paulista, Bauru, 2017.

REID, D. V.; HODSON, D. Ciência para todos en secundaria. Madrid: Narcea, 1993.

ROSA, J. M. A apropriação dos princípios fundamentais da teoria da evolução e os alcances abstrativos na concepção de mundo. 2018. 256 f. Tese (Doutorado em Educação Escolar) - Faculdade de Ciências e Letras, Universidade Estadual Paulista, Araraquara, 2018.

ROSA, J. M.; MARTINS, L. M. Reflexões sobre o ensino da taxonomia e da sistemática filogenética e o desenvolvimento do pensamento abstrato. Obutchénie: R. de Didat. e Psic. Pedag. Uberlândia, v. I, n. 2, p. 376 - 410, maio/ago. 2017. 
SANTOS, C. S. Ensino de Ciências: abordagem histórico crítica. Campinas: Armazém do Ipê, 2005.

SAVIANI, D. Pedagogia histórico-crítica: primeiras aproximações. I I. ed. Campinas: Autores Associados, 2011 .

SAVIANI, D. Escola e democracia: teorias da educação, curvatura da vara, onze teses sobre a educação política. 39. ed. Campinas: Autores Associados, 2012.

SILVA, E. M. O trabalho educativo e a natureza humana: fundamentos ontológicos da pedagogia histórico-crítica. 2017 . I 5 f. Tese (Doutorado em Educação Escolar) - Faculdade de Ciências e Letras, Universidade Estadual Paulista, Araraquara, 2017.

TAFFAREL, C. N. Z. Teoria pedagógica marxista, educação e luta de classes. In: DOS SANTOS, C. F. (org.). Crítica ao esvaziamento da educação escolar. Salvador: EDUNEB, 20 I3. p. 17-36. 